\title{
Medication adherence in patients with type 2 diabetes mellitus treated at primary health clinics in Malaysia
}

This article was published in the following Dove Press journal:

Patient Preference and Adherence

14 June 2013

Number of times this article has been viewed

\author{
Nur Sufiza Ahmad' \\ Azuana Ramli' \\ Farida Islahudin ${ }^{2}$ \\ Thomas Paraidathathu ${ }^{2}$ \\ 'Pharmaceutical Services Division, \\ Ministry of Health, Petaling Jaya, \\ Malaysia; ${ }^{2}$ Faculty of Pharmacy, \\ Universiti Kebangsaan Malaysia, Kuala \\ Lumpur, Malaysia
}

Purpose: Diabetes mellitus is a growing global health problem that affects patients of all ages. Even though diabetes mellitus is recognized as a major chronic illness, adherence to antidiabetic medicines has often been found to be unsatisfactory. This study was conducted to assess adherence to medications and to identify factors that are associated with nonadherence in type 2 diabetes mellitus (T2DM) patients at Primary Health Clinics of the Ministry of Health in Malaysia.

Materials and methods: The cross-sectional survey was carried out among T2DM patients to assess adherence to medication in primary health clinics. Adherence was measured by using the Medication Compliance Questionnaire that consists of a total of seven questions. Other data, such as patient demographics, treatment, outcome, and comorbidities were also collected from patient medical records.

Results: A total of 557 patients were recruited in the study. Approximately 53\% of patients in the study population were nonadherent. Logistic regression analysis was performed to predict the factors associated with nonadherence. Variables associated with nonadherence were age, odds ratio 0.967 (95\% confidence interval [CI]: 0.948-0.986); medication knowledge, odds ratio 0.965 (95\% CI: 0.946-0.984); and comorbidities, odds ratio 1.781 (95\% CI: 1.064-2.981).

Conclusion: Adherence to medication in T2DM patients in the primary health clinics was found to be poor. This is a cause of concern, because nonadherence could lead to a worsening of disease. Improving medication knowledge by paying particular attention to different age groups and patients with comorbidities could help improve adherence.

Keywords: type 2 diabetes mellitus, adherence, glycemic control, primary care

\section{Introduction}

The epidemic of type 2 diabetes mellitus (T2DM) has become a major concern because it affects all age groups. The incidence of diabetes was estimated to have risen by $55 \%$ between 1995 and 2010. ${ }^{1}$ The global figure is set to rise from 220 million in 2010 to 300 million in $2025,{ }^{2}$ further demonstrating the large impact of T2DM on the growing population. It is not surprising that T2DM is, at present, one of the most prevalent chronic diseases. Interestingly, it is strongly associated with obesity and a sedentary lifestyle; ${ }^{3}$ thus, lifestyle modification is an important step in addressing this issue. However, controlling blood glucose through lifestyle modification alone is a challenging feat; therefore, a more rapid method of controlling blood glucose is required. The use of medication is thus vital in the management of T2DM. However, the effectiveness of the treatment is largely dependent on the level of adherence toward prescribed medication. ${ }^{4}$
Correspondence: Thomas Paraidathathu Faculty of Pharmacy, Universiti Kebangsaan Malaysia, Jalan Raja Muda Abdul Aziz 50300, Kuala Lumpur, Malaysia

Tel +60392897484

Fax +6032698 327I

Email thomas@pharmacy.ukm.my 
Adherence is defined as the extent to which a person's behavior in terms of taking medications, following diets, or executing lifestyle changes coincides with medical or health advice. ${ }^{5}$ Apart from lifestyle modifications, adherence to medication treatment is essential in order to obtain the full therapeutic benefit of diabetes management. Adherence with regard to medication is a serious problem especially for patients with chronic diseases such as T2DM, hypertension, ischemic heart disease, and bronchial asthma. Previous work on patients with diabetes mellitus, asthma, and hypertension in a primary health clinic in Malaysia demonstrated that more than half of the study population was nonadherent to their medication. ${ }^{6}$

Current methods used to assess adherence have been through the use of direct or indirect techniques. However, at present, there is no gold standard available for measuring medication adherence. Interestingly, questionnaires have been found to provide a more accurate assessment of adherence in comparison with other methods such as pill counts or biological assays. ${ }^{7}$ They provide greater sensitivity and specificity than any other technique. ${ }^{8,9}$

Adherence to medication is influenced by several factors such as lack of information, complexity of regimen, concomitant disease, perceptions of benefit, side effects, medication cost, and emotional well being. ${ }^{10,11} \mathrm{~A}$ few studies have also identified age as a factor that influenced adherence. ${ }^{11-13}$ However, race and sex were not consistently associated with the level of patient adherence. ${ }^{14} \mathrm{~A}$ diabetic patient with other concomitant disease usually requires several drugs to achieve glycemic goals and clinical targets. The complex regimens often required to achieve the desired level of glycemic control poses a challenge for patients..$^{13,15}$ Therefore, this study was performed to assess adherence to medication among T2DM patients at primary health clinics and to identify the factors associated with nonadherence.

\section{Materials and methods}

This cross-sectional survey was performed within a 6-month period in seven Ministry of Health Primary Health Clinics in Hulu Langat, Selangor, Malaysia. These were public health clinics that supported patients within the vicinity for various diseases including T2DM. Patients attended the clinic at appointed times determined by the health care officers for continuous monitoring and consultation regarding their disease.

There were 9600 diabetic patients registered in Hulu Langat District. The sample size was calculated by using Krejcie and Morgan's ${ }^{16}$ formula. Based on this calculation, the sample size was 376 (at 95\% confidence and 5\% margin of error). However, a higher sample size of approximately 600 patients was targeted to cater for potential $20 \%$ dropout, a better power of the study with the increased number of subjects, and the need to perform subgroup analysis. Each clinic was allocated 4 weeks for patient selection and data collection. Data collection at the seven clinics took 28 weeks to complete.

Patients were included after they gave both oral and written informed consent. Patients who were included in the study were identified through a systematic random sampling of every fifth T2DM patient who attended the clinic based on their scheduled appointments as well as inclusion and exclusion criteria. Patients who were included were all T2DM patients over 20 years of age, with ongoing treatment. Patients who had incomplete medical records, who had mental problems, or who were not able to answer the questionnaire were excluded. Interviews were conducted to obtain patient demographic data, medication knowledge, and assessment of adherence through the Medication Compliance Questionnaire (MCQ). Comorbidities included in the study were hypertension, dyslipidemia, or both.

The medication knowledge consisted of five specific items of information regarding the patient's medication: name, dose, frequency, indication, and how the patient administered the medication. The knowledge score was calculated based on the number of questions answered correctly. Each correct answer was given a score of "1," with a total score of "5." The medication knowledge was then calculated as a percentage of correct answers.

Medication adherence was assessed by using a validated questionnaire (MCQ) that was developed by using the Morisky self-reporting scale, ${ }^{17}$ Hill-Bone Compliance to High Blood Pressure Therapy Scale, ${ }^{18}$ and Morisky Medication Adherence Scale. ${ }^{19}$ The MCQ was similar to the three aforementioned questionnaires, but it had minor changes in vocabulary for better understanding of the local respondents. However, the essence of each question in the original questionnaire was maintained. There were a total of seven questions in the MCQ. Questions in the MCQ assessed patients' intentional and unintentional nonadherence to medication instructions including reasons for nonadherence. A 4-point Likert scale was appointed for each question: none of the time $=4$; sometimes (one to four times per month) $=3$; most of the time (more than five times per month or more than two times per week) $=2$; all the time $=1$. The total scores were added for each patient. The scores may range from 7 (minimum) to 28 (maximum). Based on the scoring 
system used in the Morisky Medication Adherence Scale, a total score of 27 and above was considered adherence. ${ }^{19}$

The validity and reliability of the MCQ was determined before its use in the study. An internal consistency test was done by using 20 patients to check the correlation among the seven questions in the MCQ. The Cronbach's $\alpha$ value was 0.782 , indicating acceptable reliability of the questionnaire. ${ }^{20}$ Interrater reliability of the two interviewers demonstrated a Cohen's kappa statistic value of 0.796 , which indicated a substantially good interrater reliability. ${ }^{21}$ Ethical approval was obtained from the Medical Research and Ethics Committee, Ministry of Health Malaysia.

\section{Statistical analysis}

The data analysis was carried out using Statistical Package for Social Science (SPSS) for Windows version 16.0.1 (2008; SPSS Inc, Chicago, IL, USA). Basic descriptive statistics using mean and standard deviation are presented for numerical data variables such as the number of drugs used and knowledge scores. The categorical data such as sex, race, age, duration of disease, body mass index, family history, comorbidities, and level of education are presented as frequency and percentage. Chi-square test was used to test the correlation between adherence and nonadherence. Statistical significance was accepted at the $95 \%$ confidence level. Binary logistic regression analysis was conducted to identify factors associated with nonadherence, while adjusting for covariates. Variables analysis with a $P$-value $<0.05$ was included in the logistic regression model analysis by using the stepwise backward likelihood ratio method to identify factors that could significantly affect nonadherence.

\section{Results}

All the patients who were invited to participate in the study agreed to participate. A total of 557 patients between 30 and 84 years of age were included in the study. The majority of the patients were women $(n=352,63.2 \%)$. Approximately half $(56.9 \%)$ of the study population were Malay, $19.9 \%$ were Chinese, and $23.3 \%$ were Indian. The mean age of the study population was $55.95( \pm 9.13)$ years (range $30-82$ years). A small percentage (3.8\%) was below the age of 40 years, $20.1 \%$ were aged between 40 and 49 years, $40.9 \%$ were aged between 50 and 59 years, and $35.2 \%$ were aged more than 60 years. Patients included in the study had been diagnosed with T2DM for 1-33 years. Approximately half (48.8\%) of the study population was diagnosed with T2DM for less than 5 years. The remaining patients had been diagnosed for 5-33 years. Obesity was observed in $47.2 \%$ of the patients, whereas $39.1 \%$ were overweight; $85.3 \%$ had comorbidities of hypertension, dyslipidemia, or both, whereas $14.7 \%$ of the patients had diabetes mellitus only. A large percentage $(89 \%)$ had attended some form of formal education such as primary education or higher.

The responses to the questions in the MCQ are presented in Tables 1 and 2. A score of 27 was considered adherence. ${ }^{19}$ In view of the necessity for strict glycemic control, it was essential that medications were adhered to in order to ensure effective treatment. There were 295 (53\%) subjects who were categorized as nonadherent. The most common reason for nonadherence was forgetting to take medication. When assessing knowledge scores (Table 3), only 84 patients were able to score more than $80 \%$. This demonstrates that a high number of patients were unable to identify the correct usage of the medication that they were taking.

Binary logistic regression was conducted to determine whether ten variable factors, ie, sex, race, body mass index, comorbidity, level of education, age, duration of diabetes mellitus, medication knowledge, number of drugs taken, and type of antidiabetic drugs could significantly predict adherence. When entered individually, of the ten factors, only three factors (age, medication knowledge, and comorbidities) were significant at the $5 \%$ level $(P<0.05)$, and these factors were included in the binary logistic model (Table 4). The three factors were significant predictors of adherence $\left(\chi^{2}=26.30\right.$, degrees of freedom $\left.=3, \mathrm{~N}=557, P<0.001\right)$. Patients with comorbidities were found to be less adherent

Table I MCQ score obtained by the patient population $(n=557)$

\begin{tabular}{lr}
\hline Questions & Mean \pm SD \\
\hline Q1: How often do you forget to take your medicine? & $3.18 \pm 0.73$ \\
$\begin{array}{l}\text { Q2: How often do you decide not to take your } \\
\quad \text { medicine? }\end{array}$ & $3.42 \pm 0.93$ \\
$\begin{array}{l}\text { Q3: How often do you miss taking your medicine } \\
\text { because you feel better? }\end{array}$ & $3.90 \pm 0.37$ \\
$\begin{array}{l}\text { Q4: How often do you decide to take less of your } \\
\quad \text { medicine? }\end{array}$ & $3.47 \pm 0.84$ \\
$\begin{array}{l}\text { Q5: How often do you stop taking your medicine } \\
\quad \text { because you feel sick due to effects of the }\end{array}$ & $3.87 \pm 0.43$ \\
$\quad$ medicine? & \\
$\begin{array}{l}\text { Q6: How often do you forget to bring along your } \\
\quad \text { medicine when you travel away from home? }\end{array}$ & $3.93 \pm 0.26$ \\
$\begin{array}{l}\text { Q7: How often do you not take your medicine because } \\
\quad \text { you run out of it at home? }\end{array}$ & $3.82 \pm 0.47$ \\
\begin{tabular}{l} 
Mean total score \\
\hline
\end{tabular}
\end{tabular}

Notes: $M C Q s$ were given scores based on a 4-point Likert scale: never $=4$ points; sometimes $(1-4$ times a month $)=3$ points; often $(>5$ times a month $)=2$ points; always (daily) $=I$ point.

Abbreviations: MCQ, Medication Compliance Questionnaire; SD, standard deviation. 
Table 2 Summary of the MCQ score and adherence status $(\mathrm{n}=557)$

\begin{tabular}{llll}
\hline $\begin{array}{l}\text { Total score } \\
\text { (28 points) }\end{array}$ & Frequency & Percentage & Status \\
\hline $28(100 \%)$ & 115 & 20.6 & Adherent \\
$27(>95 \%)$ & 148 & 26.6 & Adherent \\
$23-26(>80 \%-95 \%)$ & 220 & 39.5 & Nonadherent \\
$18-22(>60 \%-80 \%)$ & 72 & 12.9 & Nonadherent \\
$<18(<60 \%)$ & 2 & 0.4 & Nonadherent \\
\hline
\end{tabular}

Note: Nonadherence is defined as a score of 26 and below, whereas adherence is defined as a patient with a score of 27 and higher.

Abbreviation: MCQ, Medication Compliance Questionnaire.

to medication. Diabetic patients with comorbidities were 1.78 (95\% confidence interval [CI]: 1.064-2.981) times more likely to be nonadherent compared with patients with T2DM only. Age was another factor related to nonadherence. A reduction in age by 1 year increased the possibility of nonadherence by 3.4\% (odds ratio 0.967 [95\% CI: 0.948-0.986]). Medication knowledge score also affected adherence, where a decrease of $1 \%$ in medication knowledge score increased the possibility of nonadherence by $3.6 \%$ (odds ratio 0.965 [95\% CI: 0.946-0.984]).

\section{Discussion}

There have been variations in results obtained regarding adherence toward medication. ${ }^{22}$ In this study, adherence was observed only in a total $47 \%$ of the study population. The poor level of adherence in this work demonstrates the lack of attention T2DM patients are giving toward their health. An almost similar result determined through the pill count method was seen in patients with diabetes mellitus, asthma, and hypertension in Malaysia, ${ }^{6,23}$ which further substantiates the need for proper medication management. Based on previous work, patient characteristics related to nonadherence have been shown to vary. In general, race and sex have not been consistently associated with the level of patient adherence. ${ }^{14,23,24}$ On the other hand, level of education has been reported to affect adherence to medication. ${ }^{24}$ In this study also, characteristics such as race, sex, duration of T2DM, body mass index, number of drugs taken, and educational level did not determine the level of adherence. Another finding that differed from previous work was the lack of significance between the number of medications and nonadherence. The number of drugs taken by patients was dependent on the severity of T2DM and comorbidities. ${ }^{10}$ According to a US survey, 50\% of diabetic patients received more than seven medications in their prescription. This included antidiabetic drugs as well as other drugs to
Table 3 Characteristics associated with adherence and nonadherence $(n=557)$

\begin{tabular}{|c|c|c|c|}
\hline Characteristic & $\begin{array}{l}\text { Nonadherent } \\
\text { n (\%) }\end{array}$ & $\begin{array}{l}\text { Adherent } \\
\text { n (\%) }\end{array}$ & $P$-value \\
\hline Sex & & & 0.191 \\
\hline Male & $116(56.6)$ & $89(43.4)$ & \\
\hline Female & $179(50.9)$ & $173(49.1)$ & \\
\hline Race & & & 0.519 \\
\hline Malay & $164(5 \mathrm{I} .7)$ & $153(48.3)$ & \\
\hline Chinese & $57(51.4)$ & $54(48.6)$ & \\
\hline Indian & $74(57.4)$ & $55(42.6)$ & \\
\hline BMI & & & 0.964 \\
\hline Normal (18.5-22.9) & $40(52.6)$ & $36(47.4)$ & \\
\hline Overweight (23-27.4) & $117(53.7)$ & $101(46.3)$ & \\
\hline Obesity ( $\geq 27.5$ ) & $138(52.5)$ & $125(47.5)$ & \\
\hline Comorbidity & & & $0.011 *$ \\
\hline No & $54(65.9)$ & $28(34.1)$ & \\
\hline Yes & $24 I(50.7)$ & $234(49.3)$ & \\
\hline Level of education & & & 0.831 \\
\hline Tertiary education & $38(53.5)$ & $33(46.5)$ & \\
\hline Secondary education & $124(53.4)$ & $108(46.6)$ & \\
\hline Primary education & $98(50.8)$ & $95(49.2)$ & \\
\hline No formal education & $35(57.4)$ & $26(42.6)$ & \\
\hline Age group (years) & & & $0.005^{*}$ \\
\hline$<40$ & $16(76.2)$ & $5(23.8)$ & \\
\hline $40-49$ & $69(61.6)$ & $43(38.4)$ & \\
\hline $50-59$ & $122(53.5)$ & $106(46.5)$ & \\
\hline$\geq 60$ & $88(44.9)$ & $108(55.1)$ & \\
\hline Duration of DM (years) & & & 0.424 \\
\hline$\leq 5$ & $152(55.9)$ & $120(44.1)$ & \\
\hline $6-10$ & $78(51.7)$ & $73(48.3)$ & \\
\hline $11-20$ & $51(46.8)$ & $58(53.2)$ & \\
\hline$>20$ & $14(56.0)$ & II (44.0) & \\
\hline $\begin{array}{l}\text { Medication knowledge } \\
\text { score (\%) }\end{array}$ & & & $0.028^{*}$ \\
\hline $0-50$ & $4(100.0)$ & - & \\
\hline $51-70$ & $66(61.7)$ & $41(38.3)$ & \\
\hline $7 I-80$ & $187(51.7)$ & $175(48.3)$ & \\
\hline $81-100$ & $38(45.2)$ & $46(54.8)$ & \\
\hline Number of drugs taken & & & 0.064 \\
\hline I & $14(70.0)$ & $6(30.0)$ & \\
\hline 2 & $53(63.1)$ & $31(36.9)$ & \\
\hline 3 & $58(63.1)$ & $53(47.7)$ & \\
\hline$>3$ & $170(49.7)$ & $172(50.3)$ & \\
\hline $\begin{array}{l}\text { Pattern of antidiabetic } \\
\text { treatment }\end{array}$ & & & 0.283 \\
\hline Monotherapy & $66(48.5)$ & $70(51.5)$ & \\
\hline $\begin{array}{l}\text { Combination oral } \\
\text { antidiabetic }\end{array}$ & $179(53.1)$ & $158(46.9)$ & \\
\hline $\begin{array}{l}\text { Combination oral } \\
\text { antidiabetic and insulin }\end{array}$ & $50(59.5)$ & $34(40.5)$ & \\
\hline
\end{tabular}

Note: *Kruskal-Wallis test; significant at $P<0.05$.

Abbreviations: BMI, body mass index; DM, diabetes mellitus.

treat comorbidities. ${ }^{10}$ Thus, the drug regimen for patients with diabetes mellitus can become complex, and adherence may definitely be a challenge for patients. ${ }^{13,25}$ Studies have previously demonstrated that patients with more than two medications were more likely to be nonadherent, especially 
Table 4 Logistic regression for factors predicting nonadherence in T2DM patients $(n=557)$

\begin{tabular}{|c|c|c|c|}
\hline Variables & $\begin{array}{l}\text { Odds } \\
\text { ratio }\end{array}$ & $\begin{array}{l}95 \% \text { confidence } \\
\text { interval }\end{array}$ & $P$-value \\
\hline Age of patients (per year) & 0.967 & $0.948-0.986$ & $0.010^{\mathrm{a}}$ \\
\hline $\begin{array}{l}\text { Medication knowledge score } \\
\text { (per each } 1 \% \text { decrease) }\end{array}$ & 0.965 & $0.946-0.984$ & $<0.00 \mathrm{I}^{\mathrm{a}}$ \\
\hline DM comorbidities status & I.78। & $1.064-2.98 \mid$ & $0.028^{a}$ \\
\hline
\end{tabular}

Notes: The final model was tested for goodness-of-fit by the Hosmer-Lemeshow test, classification table, and area under the receiver operating characteristics curve. ap $<0.05$ is considered significant.

Abbreviations: T2DM, type 2 diabetes mellitus; DM, diabetes mellitus.

the elderly. ${ }^{6}$ However, there was no difference in the level of adherence in patients with a higher number of medications in this study group.

Many factors can directly or indirectly influence patient adherence. This study analyzed patient characteristics in determining adherence in T2DM. Logistic regression analysis demonstrated that age, medication knowledge scores, and T2DM with comorbidities were predictors of adherence in both univariate and multivariate analysis, which further substantiates these findings. This study also indicates that, with the increase in age, the adherence to medication improved. Similar results were observed from a study among diabetic patients in a hospital in France, which showed that noncompliers were largely younger patients. ${ }^{13}$ It is possible that the younger patients were less aware of their disease and were thus more likely to be more nonadherent. This particular scenario observed in this present study emphasizes the need for educating the younger generation. Another risk factor for nonadherence was the presence of comorbidities. T2DM patients with comorbidities generally have more drugs of different pharmacological classes such as hypertensive drugs, lipidlowering agents, and antiplatelet drugs. This complex treatment regimen could be a factor that contributes toward nonadherence. Previous studies that have shown reduced adherence in patients with comorbidities due to multiple medications ${ }^{10,11,14}$ support the current findings. A third factor determining adherence was medication knowledge. In this study, a very small percentage of patients $(2.5 \%)$ reported a perfect medication knowledge score. The direct association between adherence and medication knowledge suggests that health care professionals are in the best position to disseminate appropriate information for better treatment outcome. Several studies have demonstrated poor understanding of medication knowledge among diabetic patients. ${ }^{26}$ To that end, patient education on medication regimens is essential in order to improve adherence.

\section{Limitations of the study}

Some of the limitations of the study were the potential inaccuracies in the responses of the patients that are inherent in any self-reported questionnaire especially in chronic disease conditions. The study included patients who had diabetes mellitus for different lengths of time (a few months to a number of years), and their perception and response to questions on adherence may differ. All the possible comorbidities (other than the three stated) were probably not captured during data collection. The study looked at a limited number of clinics in a specific district, and caution should be exercised in extrapolating the results.

\section{Conclusion}

This work provides an understanding of the extent of nonadherence in T2DM patients in primary health care clinics. Adherence to medications in T2DM patients remains unsatisfactory and, as a consequence, results in wastage of medications and less than optimal outcomes. The determinants of medication nonadherence were age, medication knowledge scores, and the presence of comorbidities. Although methods involved in adherence studies differ, the level of adherence identified in this study was similar to previous findings. Poor adherence among T2DM patients from primary health care clinics demonstrates the need to focus on this group of patients in order to improve treatment. Improving medication knowledge is shown as an important method in promoting adherence in T2DM patients. Particular focus is required for patients with comorbidities. Thus, this study provides a deeper understanding of adherence in T2DM patients and ways in which to overcome this setback.

\section{Acknowledgments}

We would like to express our gratitude to the Director General of Health, Ministry of Health Malaysia for his kind permission to publish this article. Our gratitude also to all members of the National Medicines Expenditure Survey (NMES) Committee, Pharmaceutical Services Division, Ministry of Health, for their views, assistance, and cooperation. Special thanks to all the staff in the primary health clinics of the Hulu Langat District for their support and commitment to this study. We are grateful to the National Institute of Health (NIH), Malaysia, for providing financial assistance through the NIH grant (NMRR-08-29-1184).

\section{Disclosure}

The authors report no conflicts of interest in this work. 


\section{References}

1. Zanariah H, Chandran LR, Wan Mohamad WB, et al. Prevalence of Diabetes Mellitus in Malaysia in 2006 - Results of the 3rd National Health and Morbidity Survey (NHMSIII). Kuala Lumpur, Malaysia: Clinical Research Centre; 2008.

2. Ooyub S, Ismail F, Daud N. Diabetes program in Malaysia - current and future. NCD Malaysia. 2004;3(2):6-12.

3. Simpson RW, Shaw JE, Zimmet PZ. The prevention of type 2 diabetes - lifestyle change or pharmacotherapy? A challenge for the 21st century. Diabetes Res Clin Pract. 2003;59(3):165-180.

4. Paes AH, Bakker A, Soe-Agnie CJ. Measurement of patient compliance. Pharm World Sci. 1998;20(2):73-77.

5. Haynes RB, Taylor DW, Sackett DL. Adherence in Health Care. Baltimore, MD: The Johns Hopkins University Press; 1979.

6. Aziz AM, Ibrahim MI. Medication noncompliance - a thriving problem. Med J Malaysia. 1999;54(2):192-199.

7. Vik SA, Maxwell CJ, Hogan DB, et al. Determinants and Health Related Outcomes Associated With Nonadherence to Prescribed Drug Regimens: A Comparison of Rural and Urban Home Care Clients. Working Paper 03-02. Edmonton, AB: Institute of Health Economics; 2003.

8. Haynes RB, Taylor DW, Sackett DL, Gibson ES, Bernholz CD, Mukherjee J. Can simple clinical measurements detect patient noncompliance? Hypertension. 1980;2(6):757-764.

9. Shalansky SJ, Levy AR, Ignaszewski AP. Self-reported Morisky score for identifying nonadherence with cardiovascular medications. Ann Pharmacother. 2004;38(9):1363-1368.

10. Rubin RR. Adherence to pharmacologic therapy in patients with type 2 diabetes mellitus. Am J Med. 2005;118 Suppl 5A:27S-34S.

11. Bartels D. Adherence to oral therapy for type 2 diabetes: opportunities for enhancing glycemic control. J Am Acad Nurse Pract. 2004; 16(1):8-16.

12. Leichter SB. Making outpatient care of diabetes more efficient: analyzing noncompliance. Clin Diabetes. 2005;23(4):187-190.

13. Bezie Y, Molina M, Hernandez N, Batista R, Niang S, Huet D. Therapeutic compliance: a prospective analysis of various factors involved in the adherence rate in type 2 diabetes. Diabetes Metab. 2006;32(6):611-616.
14. Osterberg L, Blaschke T. Adherence to medication. $N$ Engl J Med. 2005;353(5):487-497.

15. Turner R, Cull C, Holman R. United Kingdom Prospective Diabetes Study 17: a 9-year update of a randomized, controlled trial on the effect of improved metabolic control on complications in non-insulindependent diabetes mellitus. Ann Intern Med. 1996;24(1 Pt 2): 136-145.

16. Krejcie RV, Morgan DW. Determining sample size for research activities. Educational and Psychological Measurement. 1970;30;607-610.

17. Morisky DE, Green LW, Levine DM. Concurrent and predictive validity of self-reported measure of medication adherence. Med Care. 1986;24(1):67-74.

18. Krousel-Wood M, Muntner P, Jannu A, Desalvo, Re RN. Reliability of a medication adherence measure in an outpatient setting. Am J Med Sci. 2005;330(3):128-133.

19. Södergård $B$, Halvarsson $M$, Tully $P$, et al. Adherence to treatment in Swedish HIV-infected patients. J Clin Pharm Ther. 2006; 31(6):605-616.

20. Hinton PR, Brownlow C, McMurray I, Cozens B. SPSS Explained. East Sussex, UK: Routledge Inc; 2004.

21. Rausch JR, Hood KK, Delamater A, et al. Changes in treatment adherence and glycemic control during the transition to adolescence in type 1 diabetes. Diabetes Care. 2012;35(6):1219-1224.

22. Cramer JA. A systematic review of adherence with medications for diabetes. Diabetes Care. 2004;27(5):1218-1224.

23. Misra R, Lagerb J. Ethnic and gender differences in psychosocial factors, glycemic control, and quality of life among adult type 2 diabetic patients. J Diabetes Complications. 2009;23(1):54-64.

24. Ramli A, Ahmad NS, Paraidathathu T. Medication adherence among hypertensive patients of primary health clinics in Malaysia. Patient Prefer Adherence. 2012;6:613-622.

25. Hankó B, Kázmér M, Kumil P, et al. Self-reported medication and lifestyle adherence in Hungarian patients with type 2 diabetes. Pharm World Sci. 2007;29(2):58-66.

26. Wan Bebalar WM. Diabetes di Malaysia: Komplikasi dan Rawatan. [Diabetes in Malaysia: Complications and Treatment.] Pulau Pinang: Universiti Sains Malaysia; 2005. Malay.
Patient Preference and Adherence

\section{Publish your work in this journal}

Patient Preference and Adherence is an international, peer-reviewed, open access journal focusing on the growing importance of patient preference and adherence throughout the therapeutic continuum. Patient satisfaction, acceptability, quality of life, compliance, persistence and their role in developing new therapeutic modalities and compounds to

\section{Dovepress}

optimize clinical outcomes for existing disease states are major areas of interest. This journal has been accepted for indexing on PubMed Central. The manuscript management system is completely online and includes a very quick and fair peer-review system. Visit http://www.dovepress.com/ testimonials.php to read real quotes from published authors. 